\title{
Pensamento Computacional e atividades com robótica para a promoção da aprendizagem sobre o significado do resto da divisão euclidiana
}

\author{
Eliel Constantino da Silva ${ }^{1}$, Sueli Liberatti Javaroni ${ }^{2}$ \\ ${ }^{1}$ Universidade Estadual Paulista (UNESP) \\ ${ }^{2}$ Universidade Estadual Paulista (UNESP) \\ elielconstantinosilva@gmail.com, sueli.javaroni@unesp.br
}

\begin{abstract}
The article describes a research carried out with students of the ninth grade of elementary school from a state school in. The data were recorded through audio and video recording, screen capture of the notebook used by the students, as well as the records written by them and are related to the work of the Euclidean division that emerged in the construction and programming activity of a traffic light. When analyzing the produced data, we can show that the activity with robotic kits potentiated the development of Computational Thinking and both contributed to the understanding of the mathematical content worked.
\end{abstract}

Resumo. Este artigo descreve uma investigação realizada com estudantes do nono ano do Ensino Fundamental de uma escola estadual paulista pertencente ao Programa Ensino Integral. Os dados foram registrados por meio da gravação de áudio e vídeo, da captura da tela dos notebooks que os estudantes utilizaram, bem como dos registros escritos por eles e são referentes ao trabalho com o significado do resto da divisão euclidiana que surgiu na atividade de construção e programação de um semáforo. Ao analisar os dados produzidos podemos evidenciar que a atividade com kits de robótica potencializou o desenvolvimento do Pensamento Computacional e ambos contribuíram para a compreensão do conteúdo matemático trabalhado.

\section{Introdução}

Neste artigo relatamos uma pesquisa realizada com estudantes do nono ano do Ensino Fundamental de uma escola pública pertencente ao Programa Ensino Integral, localizada em um município no interior do estado de São Paulo. Pesquisamos acerca das potencialidades do desenvolvimento do Pensamento Computacional ao se trabalhar com atividades investigativas para o ensino de conteúdos matemáticos. Observamos de forma participativa quatro turmas de estudantes e desenvolvemos quatro planos de aula nessas turmas. 
VII Congresso Brasileiro de Informática na Educação (CBIE 2018)

Anais do XXIX Simpósio Brasileiro de Informática na Educação (SBIE 2018)

Apresentaremos dados referentes ao trabalho com o significado do resto da divisão euclidiana que surgiu na atividade de construção e programação de um semáforo com kit de robótica Arduino Uno. O objetivo da pesquisa realizada foi analisar o processo pelo qual esses estudantes aprendem conteúdos matemáticos ao realizarem atividades com robótica que privilegiam o desenvolvimento do Pensamento Computacional.

Para darmos andamento ao projeto de pesquisa, realizamos um levantamento bibliográfico em bases de teses e dissertações, buscando trabalhos que tinham os temas Pensamento Computacional, kit de robótica Arduino e aprendizagem de conteúdos matemáticos relacionados no mesmo contexto, para enfatizar a necessidade da abordagem adotada nesta pesquisa que está sendo aqui relatada.

$\mathrm{Na}$ ocasião do levantamento bibliográfico realizado não encontramos trabalhos relacionados no Portal Domínio Público, do Governo Brasileiro, na Biblioteca Digital Brasileira de Teses e Dissertações (BDTD) e no Repositório Institucional UNESP, de modo que todos os temas estivessem abordados no mesmo trabalho.

Encontramos, na BDTD, Biblioteca Digital USP e Repositório da Produção Científica e Intelectual da UNICAMP, trabalhos que abordavam esses temas, porém, não os abordavam todos juntos no mesmo contexto, como pode ser observado no trabalho de Costa (2018), Rodrigues (2017), Rocha (2017), Medeiros Neto (2017), Oliveira (2017), Silva (2016), Bozolan (2016), Stella (2016), Lima (2015), Ripardo (2014) e Romão (2013).

Assim, salientamos a necessidade de uma abordagem nova, uma vez que as pesquisas encontradas nas bases de dissertações e teses investigadas, com os termos de busca mencionados, não entrelaçam o Pensamento Computacional desenvolvido ao se utilizar Kit de robótica Arduino e a linguagem de programação presente no software S4A, no processo de Aprendizagem Matemática com estudantes do nono ano do Ensino Fundamental. Além disso, nenhum dos trabalhos encontrados abordaram os conteúdos acerca do resto da divisão euclidiana e seu significado.

Dessa forma, lançamo-nos ao desafio de investigar possibilidades do ensino da divisão euclidiana com atividades de robótica. Dessa maneira, realizamos observação participante na disciplina Práticas de Matemática da grade curricular dos estudantes do nono ano do ensino fundamental. Essa disciplina tem por objetivo trabalhar conteúdos matemáticos os quais os estudantes apresentam dificuldades de aprendizado, segundo a professora responsável pela disciplina de Matemática, já que no Programa de Ensino Integral, as disciplinas Práticas de Matemática e Matemática procuram estabelecer uma sinergia na busca da aprendizagem dos estudantes.

Nesta disciplina, Práticas de Matemática, o docente responsável pode ministrar os conteúdos indicados pelo professor de Matemática, abordando-os com recursos e metodologias de ensino que considerar pertinente para seu trabalho, podendo por exemplo fazer uso de jogos, tecnologia, listas de exercícios, etc. Assim, em comum acordo com esse professor propusemos o uso do Kit de robótica Arduíno Uno na busca de propiciar o ensino dos conteúdos matemáticos a serem abordados, de forma a propiciar o desenvolvimento do pensamento computacional desses discentes. 
VII Congresso Brasileiro de Informática na Educação (CBIE 2018)

Anais do XXIX Simpósio Brasileiro de Informática na Educação (SBIE 2018)

Dentre os conteúdos que precisariam ser trabalhados, o estudo da divisão euclidiana e o significado do resto era uma necessidade apontada, já que os estudantes da disciplina Práticas de Matemática, o estudo do significado do resto da divisão euclidiana era um deles, já que os estudantes do nono ano do Ensino Fundamental apresentavam dificuldades nas aulas de Matemática. Com isso, as ações foram elaboradas pensando em trabalhar esse conteúdo, tendo como plano de fundo, o desenvolvimento do Pensamento Computacional.

Desta maneira, foram elaborados em conjunto com a professora da disciplina Práticas de Matemática, quatro Planos de Aula: o Plano de Aula 1 consistia em uma ambientação à linguagem de programação presente no software Scratch, pois essa era a mesma linguagem de programação que seria utilizada para a programação dos protótipos (modelos de robôs em diversos formatos), através do software Scratch for Arduino (S4A); o Plano de Aula 2 consistia em uma ambientação com o kit de robótica e a forma de comunicação entre a placa Arduino, os demais componentes do kit de robótica e o software S4A; o Plano de Aula 3 foi elaborado visando abordar o significado do resto da divisão euclidiana através da programação de um semáforo montado com o kit de robótica; e o Plano de Aula 4 foi elaborado visando abordar a congruência entre dois números (módulo n), também utilizando a programação do semáforo, dando uma sequência ao que foi desenvolvido no Plano de Aula 3. Em todos os momentos, os estudantes trabalharam em duplas e trios.

Para o registro do trabalho dos estudantes, ao desenvolver as atividades, foi utilizado o software FlashBack Express ${ }^{1}$ que permite a captura da tela do computador em que está sendo executada as atividades, além de permitir também a gravação em áudio e vídeo das falas e imagens dos usuários do computador. Além disso, utilizamos a análise dos documentos produzidos pelos estudantes durante o desenvolvimento dos cálculos e gravamos em vídeo a dinâmica da sala de aula.

Neste artigo relatamos e analisamos o desenvolvimento do Plano de Aula 3. As ações que realizamos nesses planos foram pensados visando propiciar aos estudantes o desenvolvimento do Pensamento Computacional ao realizarem as atividades, buscando por indícios de contribuição à aprendizagem desses conteúdos para os estudantes cursantes.

\section{Pensamento Computacional}

Diversos autores têm procurado definir ou conceituar o Pensamento Computacional com base em sua área de atuação e experiências. Acreditamos que não há uma definição exata para esse termo. Jeannette Wing cunhou o termo "Pensamento Computacional" afirmando que ele "se baseia no poder e nos limites de processos de computação, quer eles sejam executados por um ser humano ou por uma máquina" (WING, 2006, p. 33). Anos depois, a autora o definiu como processos de pensamento envolvidos na formulação de problemas e suas soluções, sendo essas soluções representadas por um agente de processamento de informações que pode não ser um computador (WING, 2016).

Entendemos o Pensamento Computacional como um processo que vai além da utilização de técnicas de programação para solucionar um determinado problema. Seu

\footnotetext{
${ }^{1}$ https://www.flashbackrecorder.com/express/
} 
VII Congresso Brasileiro de Informática na Educação (CBIE 2018)

Anais do XXIX Simpósio Brasileiro de Informática na Educação (SBIE 2018)

foco está centrado nas ideias, na compreensão, no conhecimento, e menos na tecnologia. Trata-se de um conjunto de capacidades intelectuais e cognitivas, como o conceituar e o pensar de maneira abstrata, atreladas à abstração computacional (pensar em códigos), que permite compreender o universo humano. É uma forma de pensar humana que complementa e combina com outras formas de pensamento, como o matemático, científico, filosófico, lógico, linguístico, tecnológico, abstrato, ou seja, trata-se de um processo transversal que faz uma ponte com outras áreas disciplinares, promovendo um cruzamento de saberes.

O pensamento é a compreensão da realidade objetiva e subjetiva e está relacionado com as abstrações; a evolução da Computação descreve "a trajetória da nossa aquisição de conhecimento com relação a como sistematizar (e se possível, automatizar) o processo de resolução de problemas" (RIBEIRO; FOSS; CAVALHEIRO, 2017, p. 03). Aho (2012) o considera como os processos de pensamento envolvidos na formulação de problemas, de modo que suas soluções possam ser representadas como passos de algoritmos.

O desenvolvimento do Pensamento Computacional é portanto, o desenvolvimento de um pensamento analítico que tem como essência a abstração; é uma maneira pela qual os humanos solucionam problemas; é o conceituar, pensar de maneira abstrata, ao invés de simplesmente utilizar técnicas de programação para solucionar um problema; é a ideia, o conceito computacional que utilizamos para resolver problemas, gerenciar nossas vidas diárias, comunicar e interagir com outras pessoas (WING, 2006). É a união do "pensamento humano com as capacidades computacionais" (PHILLIPS, 2009).

E por esse motivo, consideramos que o Pensamento Computacional não está atrelado apenas à resolução de problemas, mas sim a toda e qualquer tarefa que exige um pensar sistemático (organizado), abstrato (dados e/ou processos) e analítico (viabilidade, eficiência, correção). Acreditamos que ao desenvolver o Pensamento Computacional, o indivíduo desenvolve o

\begin{abstract}
[...] pensamento abstrato (utilização de diferentes níveis de abstração para perceber os problemas e, passo a passo, soluciona-los), o pensamento algorítmico (expressão de soluções em diferentes passos de forma a encontrar a forma mais eficaz e eficiente de resolver um problema), o pensamento lógico (formulação e exclusão de hipóteses) e o pensamento dimensionável (decomposição de um grande problema em pequenas partes ou composição de pequenas partes para formular uma solução mais complexa) (SOUSA; LENCASTRE, 2016, p. 257)
\end{abstract}

Com base nas concepções apresentadas e em nossas pesquisas realizadas em aulas de Matemática da Educação Básica, entendemos o Pensamento Computacional como um processo de pensamento que envolve fortemente a organização lógica de dados, o pensar recursivamente, a reformulação de um problema complexo em problemas que saibamos ou que, provavelmente, consigamos resolver (composição e decomposição de tarefas), o representar dados através de abstrações, simulações, generalizações e a interpretação de dados como programas e programas como dados, não sendo essencial a utilização do computador, mas sim a compreensão dos aspectos da computação. 
VII Congresso Brasileiro de Informática na Educação (CBIE 2018)

Anais do XXIX Simpósio Brasileiro de Informática na Educação (SBIE 2018)

\section{Estudo do significado do resto da divisão euclidiana}

Como já exposto, inicialmente desenvolvemos com os estudantes uma ambientação do kit de robótica. Na sequência, os estudantes agrupados em duplas ou trios, montaram o protótipo que seria criado. Após esses momentos, os estudantes montaram o protótipo de um semáforo de três tempos, utilizando os LED vermelho, amarelo e verde, resistores, jumpers, placa Protoboard e a placa Arduino Uno, como podemos observar na Figura 1, a seguir:

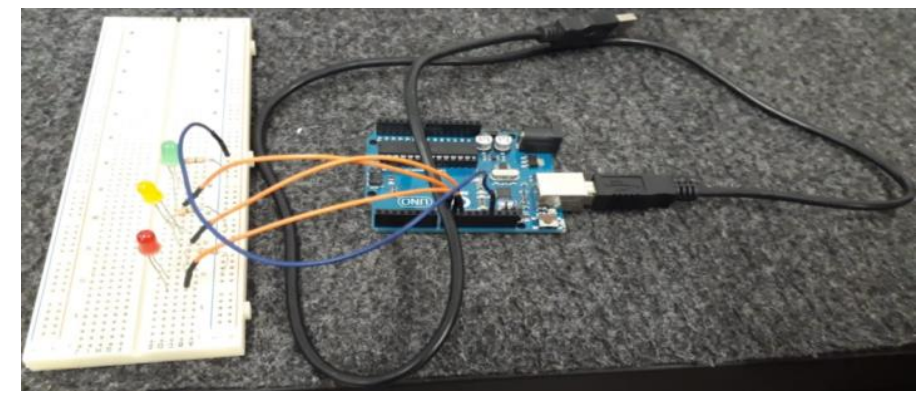

Figura 1. Semáforo construído com o kit de robótica Arduino Uno

Em seguida, cada dupla de estudantes propôs um programa elaborado no ambiente Scratch. A Figura 2, a seguir, ilustra três dos programas elaborados por três duplas de estudantes. A condição imposta por nós é que o LED vermelho tinha que estar aceso por 5 segundos, o LED verde por 4 segundos e o LED amarelo por 3 segundos, ou seja, o período de funcionamento do semáforo seria 12 segundos. Algumas das programações realizadas pelos estudantes podem ser observadas na figura, a seguir:

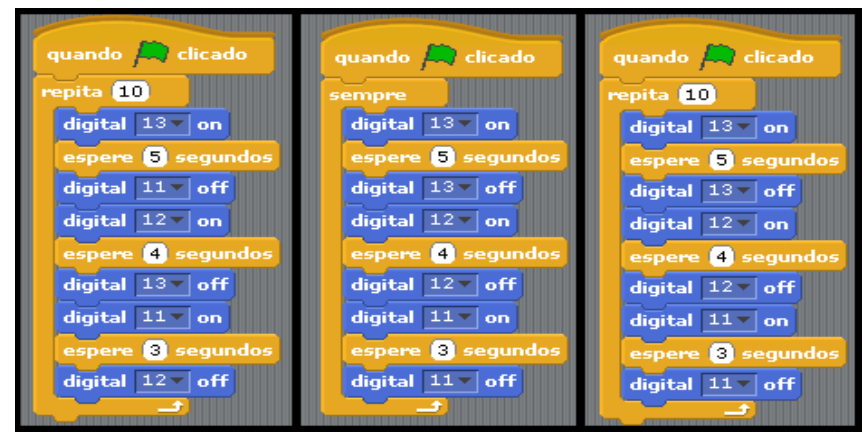

Figura 2. Programação do semáforo realizada pelos estudantes. Da esquerda para a direita: programação $A$; programação $B$; e programação $C$.

Nos três programas $\mathrm{A}, \mathrm{B}$ e $\mathrm{C}$, desenvolvidas pelos estudantes, que pode ser observado na Figura 2, a entrada/saída digital 13 corresponde ao LED vermelho, a entrada/saída digital 12 corresponde ao LED verde e a entrada/saída digital 11 corresponde ao LED amarelo.

No processo de construção da programação para que o semáforo funcionasse, foi possível observar na interação e nas falas dos estudantes com seus pares de dupla/trio e com as outras duplas/trios de estudantes, que antes de iniciarem a programação, eles planejaram o que iriam fazer, organizaram as informações que tinham e decompuseram 
VII Congresso Brasileiro de Informática na Educação (CBIE 2018)

Anais do XXIX Simpósio Brasileiro de Informática na Educação (SBIE 2018)

o problema (programar o semáforo de acordo com a condição imposta à eles) em partes menores: i) programar o LED vermelho, ii) programar o LED verde e iii) programar o LED amarelo, entre outras divisões, de modo que eles conseguissem desenvolver toda a programação para que o semáforo, de fato, funcionasse.

Nesse processo, observávamos que novas ideias iam surgindo nos diálogos dos estudantes, a cada verificação da conjectura que eles iam criando no desenvolvimento da programação. Esse processo de pensamento não foi linear, foi sendo desenvolvido ao passo que os estudantes articulavam o que estavam pensando e abstraindo com aquilo que estavam vendo (protótipo) que dava à eles o feedback das suas conjecturas, direcionando os próximos passos deles em relação a como proceder para programar, ou seja, provocava nos estudantes o pensar sobre o pensar a todo instante.

Ao término da programação do semáforo, colocamos aos estudantes a seguinte questão: "Quando eu sair da escola, o semáforo começará a funcionar. Em x minutos chegarei ao semáforo. Em qual cor estará o funcionamento do semáforo? ". Para cada grupo de estudantes determinamos um tempo diferente para a chegada ao semáforo, propiciando assim que eles realizassem seus cálculos e discutissem acerca da atividade.

Para que eles pudessem responder ao desafio posto, eles precisariam entender a programação do semáforo como um evento cíclico, cujo período é 12 segundos. Portanto, para saber a cor que estaria em funcionamento no semáforo após $\mathrm{x}$ minutos, bastava converter esse tempo em segundos e dividi-lo por 12 segundos. O quociente da divisão determinaria a quantidade de vezes que o evento cíclico ocorreu, isto é, a quantidade de vezes que o semáforo funcionou completamente e o resto determinaria quanto segundos a mais o semáforo funcionaria, após a última vez que ele realizou o período completo de funcionamento. $\mathrm{O}$ valor do resto indicaria em qual segundo estaria a programação no tempo indicando, mostrando a cor que estaria em funcionamento.

Esse momento de investigação dos estudantes não ocorreu de modo linear. Em todo tempo, eles procuravam relacionar o funcionamento dos componentes do protótipo com o programa que havia elaborado no S4A. Buscavam relacionar também o funcionamento do semáforo com a divisão euclidiana que eles esboçavam em seus cadernos.

Alguns estudantes tentaram resolver a questão colocada utilizando, primeiramente a programação. Executaram a programação e ficaram observando o que acontecia. Perceberam que a cada 12 segundos, a programação se repetia e começaram a contar através do cronômetro do celular ou mesmo marcando em uma folha, a quantidade de vezes que a programação, 12 segundos, se repetiria e, através de somas sucessivas, foram somando o número 12 até obter a quantidade que se queria.

Após esse movimento de pensar no problema, alguns estudantes perceberam que deveriam converter o tempo que foi dado em minutos para segundos e, então, recorrendo a conceitos matemáticos já estudados em anos anteriores, fizeram essa conversão. Porém, nem todos os estudantes tiveram essa percepção e a estes, colocamos indagações que os fizessem mobilizar os conhecimentos prévios adquiridos em anos anteriores, com a finalidade de perceberem que teriam que fazer a conversão do tempo dado. 
VII Congresso Brasileiro de Informática na Educação (CBIE 2018)

Anais do XXIX Simpósio Brasileiro de Informática na Educação (SBIE 2018)

Foi possível observar os estudantes conjecturando, criando relações com conhecimentos que eles possuíam, relacionando tais conhecimentos com aquilo que eles conjecturavam ser o correto e ao passo que executavam o raciocínio construído, foram criando conexões mentais através da mobilização de pensamentos que permitiram perceber que deveriam realizar a conversão do tempo e a continuidade da resolução da questão.

Os estudantes que perceberam, inicialmente, que teriam que transformar minutos em segundos e resolveram por somas sucessivas, foram analisando a execução da programação pelo protótipo, somando os 12 segundos a cada vez que ocorria a programação completa, até observarem a cor que estaria acesa quando a contagem chegasse nos segundos que se queria.

Após conseguirem responder a primeira questão, colocamos a mesma questão novamente, porém, com uma duração de tempo maior para chegar até o semáforo, de modo que os provocassem a pensar em alternativas. Foi nesse momento, que junto com seus pares, começaram a perceber que o uso da divisão euclidiana poderia ser um recurso.

Mas, para chegar a essa percepção, alguns estudantes perceberam que ao somar o número 12 várias vezes, o que estava sendo realizado era a multiplicação do número 12 pela quantidade de vezes que ele repetia na soma sucessiva. Desta maneira, começaram a multiplicar o número 12 por vários números de modo a encontrar o número que mais se aproximasse daquele que se queria, para saberem quantas vezes a programação completa aconteceria e, após isso, bastava analisar a execução da programação pelo protótipo, esperar ocorrer o número de vezes que encontraram que ocorreria a programação completa e, depois, contar os segundos que faltariam.

Ao tentar descobrir quantas vezes teriam que multiplicar o número 12 , os estudantes começaram a utilizar a divisão euclidiana, dividindo o tempo, em segundos, que eles tinham como dado da questão, por 12, que era o tempo total de execução da programação. Nesta divisão, encontravam o número de vezes que o 12 repetiria e então, multiplicavam o 12 por aquele número e prosseguiam da mesma maneira que descrevemos no parágrafo anterior, ou seja, esses estudantes que procederam desta maneira, ainda não tinham compreendido a parte conceitual do algoritmo da divisão euclidiana.

Interagindo com seus pares e observando a programação, os estudantes perceberam que poderiam trocar o bloco "sempre" pelo bloco "repita vezes", no software S4A, de modo que, ao invés de ficarem olhando o semáforo executar a programação ao mesmo tempo em que eles vão contando quantas vezes a programação completa já aconteceu, eles poderiam programar para que o semáforo executasse a programação completa o número de vezes exato que eles queriam. Dessa forma, perceberam que o quociente da divisão euclidiana determinava o número de vezes que a programação seria executada completamente.

Houve estudantes que no início da resolução da segunda questão perceberam que ela poderia ser resolvida utilizando a divisão, principalmente aqueles que já tinham realizado a construção do algoritmo utilizando o bloco "repita vezes". A dificuldade foi em encontrar como determinar a cor que estaria acesa no semáforo após x segundos. 
VII Congresso Brasileiro de Informática na Educação (CBIE 2018)

Anais do XXIX Simpósio Brasileiro de Informática na Educação (SBIE 2018)

Começaram, então, observar a programação e relacionar cada parte do algoritmo da divisão euclidiana com o algoritmo que desenvolveram. Alguns dos estudantes alteraram sua programação a fim de buscarem determinar a cor do semáforo em determinada situação.

Finalmente, alguns estudantes perceberem que existia uma possível relação entre o resto da divisão euclidiana e o funcionamento do semáforo programado. No entanto, esse processo de perceber o ocorrido não foi linear. Eles transformavam os minutos em segundos, dividiam os segundos por 12, programavam para que o semáforo repetisse a volta completa de acordo com o valor encontrado no quociente e iam observando a programação e a execução da programação pelo protótipo.

Alguns estudantes perceberam que a determinação da cor era algo que acontecia após a programação ser executada a quantidade de vezes determinada pelo quociente e, por isso, prosseguiram na divisão dos segundos por 12, de modo que o quociente se tornara um número decimal e começaram a relacionar esse número decimal com o que estava sendo desenvolvido pelo protótipo e aqui tiveram que mobilizar outros conceitos já adquiridos em anos anteriores.

Precisaram lembrar que um número decimal é composto por uma parte inteira e por uma parte decimal. No exemplo dado anteriormente, 74 segundos divido por 12 , obteríamos o quociente igual a 6,16, que representaria 6 partes inteiras somado com 0,16 . Alguns estudantes apresentaram dificuldade nesse processo, mas conseguiram compreender e entender que o número de vezes que a programação seria executada completamente seria 6 , ressignificando o conceito de parte inteira de um número decimal, e começaram a conjecturar que 0,16 representaria a cor que estaria o semáforo ao final dos 74 segundos. Muitos tentaram encontrar uma relação usando o quociente em decimal, mas não conseguiram.

Em todas as turmas tiveram estudantes que conseguiram perceber que existia uma relação com o resto da divisão euclidiana, mas, isso aconteceu após eles programarem o protótipo para funcionar em diversos e diferentes segundos. Começaram a observar que quando a programação parava nos comandos referentes ao LED vermelho, o resto era sempre 1,2, 3, 4 ou 5; quando a programação parava nos comandos referentes ao LED verde, o resto era sempre $6,7,8$ ou 9; e quando a programação parava nos comandos referentes ao LED amarelo, o resto era sempre 10, 11 ou 12.

Concluíram, portanto, que o que determinava a cor era o resto da divisão euclidiana por 12, para esse caso do semáforo. Aos poucos, aqueles que chegaram a essa conclusão foram explicando aos colegas até que todos da turma compreenderam que esse era um possível significado para o resto da divisão euclidiana.

Em uma das turmas, tiveram estudantes que generalizaram e aplicaram esse conteúdo com a data de aniversário, em que o evento cíclico passou a ser a semana do mês, com período igual a 7 e o resto da divisão por $28,29,30$ ou 31 , dependendo do mês e do ano considerado, determinava o dia da semana em que a pessoa nasceu, sendo que o resto 1 corresponderia ao dia da semana em que começou o mês 
VII Congresso Brasileiro de Informática na Educação (CBIE 2018)

Anais do XXIX Simpósio Brasileiro de Informática na Educação (SBIE 2018)

\section{Conclusão}

Neste artigo apresentamos e discutimos uma atividade com kit de robótica desenvolvida por duplas e trios de estudantes do nono ano do Ensino Fundamental de uma escola pública estadual pertencente ao Programa Ensino Integral. Esse trabalho com os alunos fez parte do cenário de investigação de uma pesquisa que buscou evidenciar indícios de aprendizagem dos estudantes ao desenvolverem atividades que priorizavam $o$ desenvolvimento do Pensamento Computacional desses estudantes ao explorarem os kits de robótica com programação no S4A.

Em todo o processo, observamos o Pensamento Computacional sendo desenvolvido pelos estudantes através das soluções que eram encontradas mediante a interação dos dados/informações processados pelo cérebro com os recursos presentes na sala de aula e seus pares.

Além dessas características, percebemos através das falas dos estudantes o desenvolvimento de uma organização lógica dos dados através de um pensar sistemático, abstração desses dados e conexões com conhecimentos já adquiridos, generalizações e a verificação de cada etapa quanto a viabilidade, eficiência e correção através de um pensar recursivamente, provocado pelo pensar sobre o pensar.

\section{Referências}

AHO, A. V. Computation and Computational Thinking. The computer journal, v. 55, n. 7, p. 832-835, 2012.

BOZOLAN, S. M. O pensamento computacional: ensino e aprendizagem através do software processing. 2016. 145f. Dissertação (Mestrado em Tecnologia da inteligência e Design Digital) - Pontifícia Universidade Católica de São Paulo, São Paulo, 2016.

COSTA, D. V. R. Programação no auxílio da resolução de situações-problema e uma abordagem para o ensino de funções afim e quadrática. 2018. 81f. Dissertação (Mestrado Profissional) - Instituto de Biociências, Letras e Ciências Exatas, Universidade Estadual Paulista "Júlio de Mesquita Filho", São José do Rio Preto, 2018.

LIMA, W. A. T. Ensinando matemática por meio de situações potencialmente adidáticas: estudo de casos envolvendo análise combinatória. 2015. 69f. Dissertação (Mestrado Profissional em Ensino de Matemática) - Instituto de Matemática e Estatística, Universidade de São Paulo, São Paulo, 2015.

MEDEIROS NETO, M. S. Protótipo robótico de baixo custo utilizado como ferramenta para o ensino de Matemática. 2017, 81f. Dissertação (Programa de Pós-Graduação Profissional em Matemática - PROFMAT) - Universidade Estadual da Paraíba, Campina Grande, 2017.

OLIVEIRA, A. D. Robótica nas aulas de Matemática: uma perspectiva tecnológica associada ao ensino de funções. 2017. 69f. Dissertação (Mestrado em Ensino de Ciências e Educação Matemática) - Universidade Estadual da Paraíba, Campina Grande, 2017. 
VII Congresso Brasileiro de Informática na Educação (CBIE 2018)

Anais do XXIX Simpósio Brasileiro de Informática na Educação (SBIE 2018)

PHILLIPS, P. Computational Thinking: a problem-solving tool for every classroom. Communications of the CSTA, v. 3, n. 6, p. 12-16, 2009.

RIBEIRO, L.; FOSS, L.; CAVALHEIRO, S. A. da C. Entendendo o Pensamento Computacional. Jul. Disponível em: <https://arxiv.org/abs/1707.00338>. Acesso em: 14 jun. 2018.

RIPARDO, R. B. Escrever bem aprendendo matemática: tecendo fios para uma aprendizagem matemática escolar. 2014. 157f. Tese (Doutorado em Educação) Faculdade de Educação, Universidade de São Paulo, São Paulo, 2014.

ROCHA, K. C. Programação em Scratch na sala de aula de matemática: investigações sobre a construção do conhecimento de ângulo. 2017. 106f. Dissertação (Mestrado em Ensino de Matemática) - Universidade Federal do Rio Grande do Sul, 2017.

RODRIGUES, S. P. A aprendizagem do conceito científico de fração por alunos com deficiências intelectual: os resultados de uma intervenção. 2017. 84f. Dissertação (Mestrado Profissional em Educação) - Universidade Federal do Pampa, Campus Jaguarão, Jaguarão, 2017.

ROMÃO, M. M. C. O método Kumon para remediação cognitiva de portadores de esquizofrenia: um ensaio clínico randomizado, controlado com placebo. 2013. 122f. Dissertação (Mestrado em Psiquiatria) - Faculdade de Medicina, Universidade de São Paulo, São Paulo, 2013.

SILVA, S. P. O uso da lógica de programação para a Educação Matemática no Ensino Médio: experiências com o Scratch. 2016. 135f. Dissertação (Mestrado em Ensino de Ciências e Matemática) - Faculdade de Educação - Universidade Federal de Pelotas, Pelotas, 2016.

SOUSA, R. M.; LENCASTRE, J. A. Scratch:uma opção válida para desenvolver o pensamento computacional e a competência de resolução de problemas. In: CARVAlHO, A. A. A. et al. (Org.). Atas do $2^{\circ}$ encontro sobre jogos e mobile learning. Braga: CIEd, 2014. p. 256-267.

STELlA, A. L. Utilizando o Pensameno Computacional e a Computação Criativa no ensino da linguagem de programação Scratch para alunos do Ensino Fundamental. 2016. 46f. Dissertação (Mestrado em Tecnologia) - Faculdade de Tecnologia, Universidade Estadual de Campinas, Limeira, 2016.

WING, J. M. Computational thinking. Commun. ACM, v. 49, n. 3, p. 33-35. 2006.

WING, J. M. Pensamento Computacional - Um conjunto de atitudes e habilidades que todos, não só cientistas da computação, ficaram ansiosos para aprender e usar. Revista Brasileira de Ensino, Ciência e Tecnologia (RBECT), Ponta Grossa, v. 9, n. 2, p. 1-10, mai./ago. 2016. 